\title{
BENEFÍCIOS AMBIENTAIS E RESULTADOS DO PROGRAMA DE INSPEÇÃO E MANUTENÇÃO DE SÃO PAULO
}

\author{
Fábio Cardinale Branco ${ }^{1}$ \\ Gabriel Murgel Branco ${ }^{2}$ \\ Marcelo Cardinale Branco ${ }^{3}$ \\ Alfred Szwarc ${ }^{4}$
}

\section{RESUMO}

O Programa de Inspeção e Manutenção de Veículos e Uso na cidade dede São Paulo (I/M-SP) vem produzindo resultados com benefícios ambientais crescentes, caracterizados por $30 \%$ a $50 \%$ de redução das emissões excessivas. A redução progressiva das médias de emissãoa cada ano indica uma nova cultura de manutenção dos veículos, melhores serviços e maior conscientização por parte da sociedade.

Os resultados também demonstram que os veículos precisam ser inspecionados desdeo primeiro ano de uso, poisas tecnologias avançadas que equipam os veículos modernos são susceptíveis a variaçõesde grande amplitude nas emissões em caso de problemas, podendo elevaras emissões de poluentesa valores dez a vinte vezes superiores aos normais. Devido o grande aumento da frota de veículos novos, os impactos do aumento na emissão são comparáveis aos dos veículos mais antigos. As características de inspeção anual exigidas pelo CONAMA possuem razões técnicas muito bem fundamentadas ecomprovadas.

Foi também constatada a importância da operação centralizada do Programa, também determinada pelo CONAMA, que é fundamental para o controle de qualidade do processo edetecção de fraudes. Os resultados obtidos, depois de aferidos e referendados por análises estatísticas e estudos técnicos também possibilitaram subsidiaro CONAMA para a atualização da legislação federal que regulamenta esse assuntoe serviramcomo informação de campo para realimentação da indústria automobilística e da rede de reparação. Esses fatos permitem afirmar que o Programa I/M-SP tem atingido resultados expressivos,comparáveis ao nível dos melhores programas internacionais.

\section{ENVIRONMENTAL BENEFITS AND RESULTS OF THE INSPECTION AND MAINTENANCE PROGRAM OF SÃO PAULO}

\begin{abstract}
The São Paulo City In-Use Vehicle Inspection and Maintenance Program -(I/M-SP) has been producing results with increasing environmental benefits ranging from $30 \%$ to $50 \%$ reductionof excess emissions. The progressive improvement in the emissions yearly averages indicates a new culture of maintenance, better services and greater awareness of society.

The results also show that the vehicles need to be inspected since the first year of use, because the advanced technologies that equip modern vehicles are susceptible to high rise of emissions in case of problemsleading to an increase of emission values from ten to twenty times than normal levels. Due to the impressive increase of new vehicles in the existing fleet the impacts of emissions growth are comparable to those of older vehicles. Therefore, the annual inspection requirements established by CONAMA are strongly supported by technical reasons and proven to be needed.

Also, it has been shown that the centralized program concept,as defined by CONAMA, is fundamental to the inspection quality control process and fraud detection. Results from the Program, after being thoroughly verified and certified by statistical analysis and technical studies also have been used by CONAMA for regulatory updates. They also have been used by the motor industry and repair networkas a field feedback. All this facts allow the authors to state that the I/M-SP Program has reached significantresults, comparableto the ones reached by the bestinternational programs of its kind.
\end{abstract}

\footnotetext{
${ }^{1}$ EnvironMentality - Consultor

'EnvironMentality - Consultor

${ }^{3}$ Consultor;até dezembro de 2012 foi Secretário Municipal dos Transportes em São Paulo

${ }^{4}$ ADS - Consultor
} 


\section{Introdução}

O Programade Inspeção e Manutenção de Veículos e Uso na cidade de de São Paulo(I/M-SP) foi adotado em 2008 pela administração municipal com o propósito de promover a melhoria dos cuidados de manutenção preventiva e corretiva da frota existente e, desta forma, prevenir e controlar o aumento das emissões de poluentes atmosféricos e de ruído causadas pelo desgaste de peças, variação na regulagem do motor, defeitos e outras causas. O Programa tem inspecionado anualmente cerca de três milhões de veículos, gerando uma base de dados de emissões extremamente consistente, que permite avaliar a real situação da frota paulistana referente ao seu estado de manutenção, efeitos das medidas governamentais de controle de emissões (ex. PROCONVE e PROMOT), resultados da introdução de novas tecnologias e combustíveis (injeção eletrônica, conversores catalíticos, veículos flex, uso de etanol etc.) e comportamento das emissões ao longo da vida útil dos veículos, dentre outros parâmetros. Issopossibilitou avaliar cada parcela das emissões em termos da emissão dos veículos em uso com a manutenção em dia edesses veículos sem a devida manutenção, permitindo dimensionar a emissão evitável, que pode ser controlada pelo I/M-SP (figura 1.1).

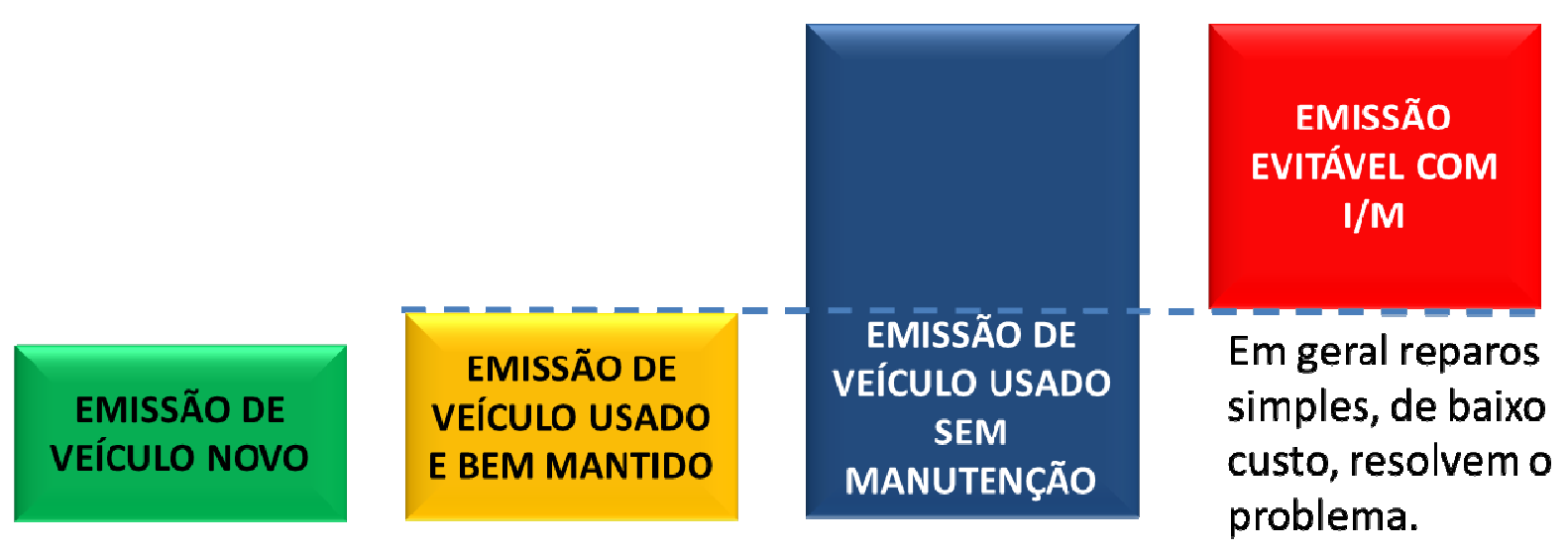

Figura 1.1 - Visão tecnológica do controle de emissão veicular

Neste trabalho serão mostrados os resultados obtidos pelo Programa I/M-SP para a redução da parcela evitávelda emissão - denominadas como benefício ambiental do Programa - através da quantificação das emissões de emissẽes dos veículos bem mantidos, daqueles sem manutenção e das reduções das emissões destes após as reinspeções a que foram submetidos.

\section{Estado geral das frotas}

A inspeção de um veículo no âmbito do Programa I/M-SP se dá em três etapas principais, iniciando-se por uma série de pré-inspeções visuais, onde é analisada a conformidade de itens facilmente verificáveis como a presença de 
fumaça azulada ou fumaça preta excessiva, fixação de mangueiras e conexões, ausência de catalisador, funcionamento sensivelmente irregular do motor, vazamentos aparentes de combustível ou óleo, entre outros. Uma vez aprovado nas pré-inspeções visuais, o veículo é submetido à medição de emissões (CO e HC para os do ciclo Otto, inclusive motociclos, e opacidade da fumaça para os do ciclo Diesel) e, finalmente, à inspeção de ruído. A inspeção de ruído é feita inicialmente de forma subjetiva pelo inspetor durante as acelerações da medição de emissões e, caso o inspetor tenha alguma suspeita de emissão de ruído acima do normal, ou se o veículo for selecionado aleatoriamente pelo sistema para inspeção objetiva de ruído, este é encaminhado para a área de medição, onde a análise é feita de acordo com o estabelecido pela Instrução Normativa № 06/2009 do IBAMA. Os veículos que não são aprovados nas pré-inspeções visuais recebem a qualificação de "rejeitados", sendo excluídos do restante do processo, enquanto que aqueles que seguem para a medição de emissão de gases ou ruído, são qualificados como "reprovados".

A análise comparativa dos resultados obtidos pelos veículos na inspeção inicial nos fornece a informação do estado geral de cada frota ao iniciar o processo anual de inspeção, o que equivale aproximadamente ao estado em que os veículos se mantém, considerando a data de início do Programa I/M-SP. (figura 2.1).

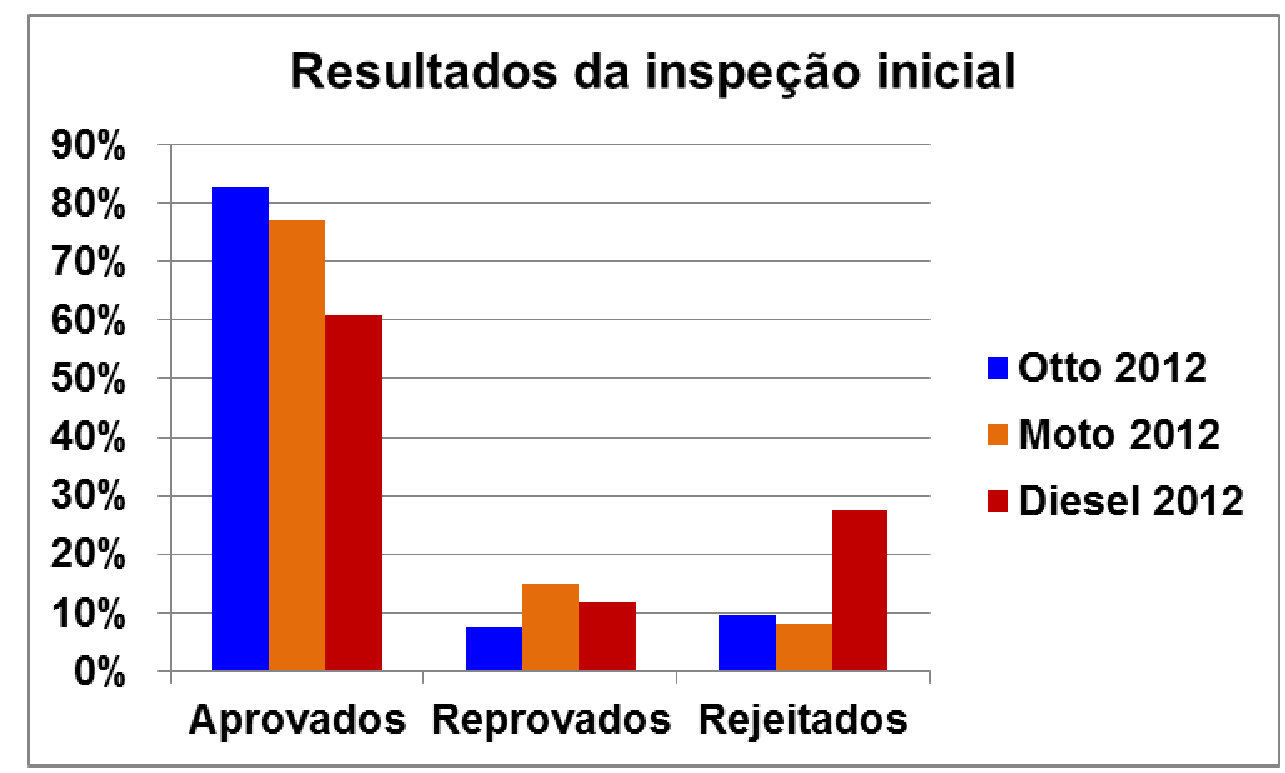

Figura 2.1 - Resultados iniciais das frotas inspecionadas

Por esta figura pode-se observar que de uma forma geral os automóveis são os mais bem mantidos, atingindo mais de $80 \%$ de aprovação inicial, enquanto que os veículos do ciclo Diesel aprovam apenas $60 \%$ na primeira inspeção, principalmente devido a problemas simples, detectados nas pré-inspeções visuais, que determinam a rejeição de quase $30 \%$ desta frota. No caso dos veículos do ciclo Diesel, os motivos que levaram à rejeição em 2012são principalmente a presença de vazamentos aparentes, a emissão de fumaça preta visivelmente muito intensa e 
avarias no sistema de admissão de ar, nesta ordem. É interessante notar que nos anos anteriores o principal motivo de rejeição dos veículos Diesel foi a emissão de fumaça preta visivelmente muito intensa, com 42.074 inspeções rejeitadas por este motivo em 2010 e 44.779 em 2011 contra apenas 17.283 em 2012.

Esses mesmos resultados podem ser estratificados em função de diversas características dos veículos, tais como ano de fabricação, ano modelo, fase do PROCONVE/PROMOT, marca etc., tanto para a inspeção inicial como para a final, fornecendo figuras como a mostrada abaixo (figura 2.2), onde é possível verificar que, embora alguns grupos tenham maiores dificuldadesde manter a conformidade com os padrões de referência de um ano para o outro (visto através da inspeção inicial), ao longo do processo é sempre possível trazê-los de volta para um estado de conformidade (mostrado pelos resultados da inspeção final).

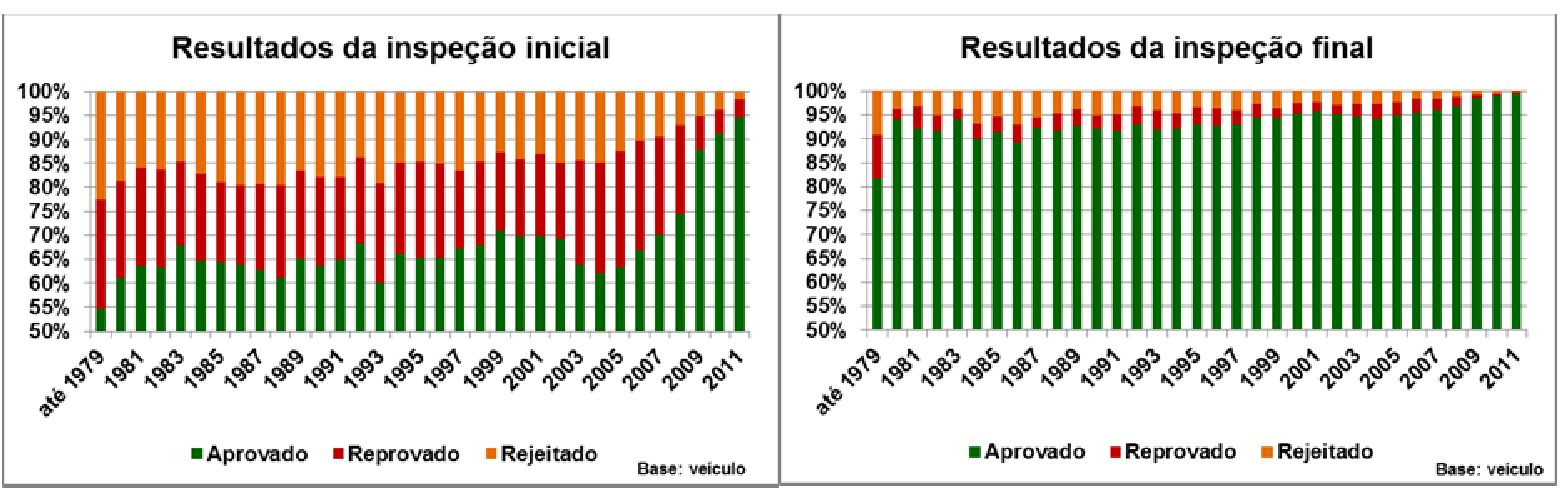

(observar que os eixos variam apenas de $50 \%$ a $\mathbf{1 0 0 \%}$ para maior clareza da figura)

Figura 2.2 - Resultados das inspeções de motociclos em geral

Outro tipo de análise que se pode extrair dos dados envolve a comparação estatística entre as duas formas de inspeção (visual e medição de gases), posto que, sendo dois enfoques diferentes para um mesmo objetivo - a verificação do estado de manutenção do veículo - eventuais discrepâncias que sejam encontradas podem se referir a problemas de procedimento na inspeção visual ou à relativa facilidade ou dificuldade de atender aos valores de referência determinados. Caso hajam problemas na inspeção visual, estes não apresentarão comportamento estatístico definido em função da idade do veículo, por exemplo, enquanto que se o problema for relativo aos valores de referência, deverão estar agrupados de acordo com a tecnologia sujeita àquele padrão em particular, conforme ilustrado na figura 2.3, para os automóveis do ciclo Otto.

Esta figura mostra uma coerência entre os percentuais de reprovação e de rejeição (ambos indicadores de mau estado de manutenção), exceto no período 1994 a 2002, onde o percentual de reprovações é desproporcionalmente menor. Este comportamento é devido a duas razões de ordem tecnológica:

- a partir de 1995, surgiram gradativamente os primeiros modelos de motores com injeção eletrônica, cuja durabilidade da regulagem se destaca dos veículos carburados. Para esta correção seria necessário estabelecer limites distintos para ambas as tecnologias; 
- a Resolução CONAMA 418/2009 revisou os parâmetros de referência somente para os modelos fabricados a partir de 2003, pois não havia dados estatísticos para dimensionar a revisão dos modelos anteriores, que ficaram relegados para uma próxima oportunidade. Cabe salientar que a tecnologia dos motores deste período é praticamente a mesma, caracterizada pela fase L3 do PROCONVE.

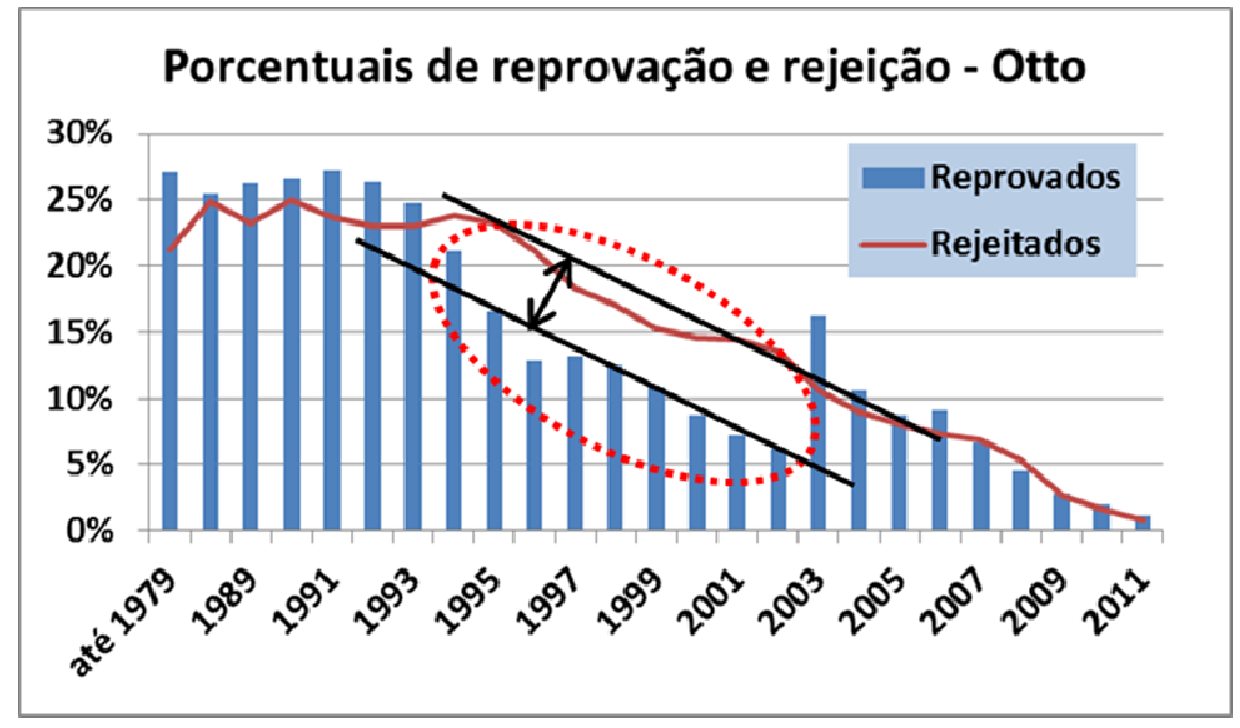

Figura 2.3 - Coerência da inspeção visual e de gases em veículos leves

Outra análise importante refere-se ao número de reinspeções necessárias para que os veículos obtenham aprovação no Programa. Esta análise mostra o grau de dificuldade que os proprietários dos veículos encontram para corrigir os problemas de manutenção detectados (figura 2.4). 


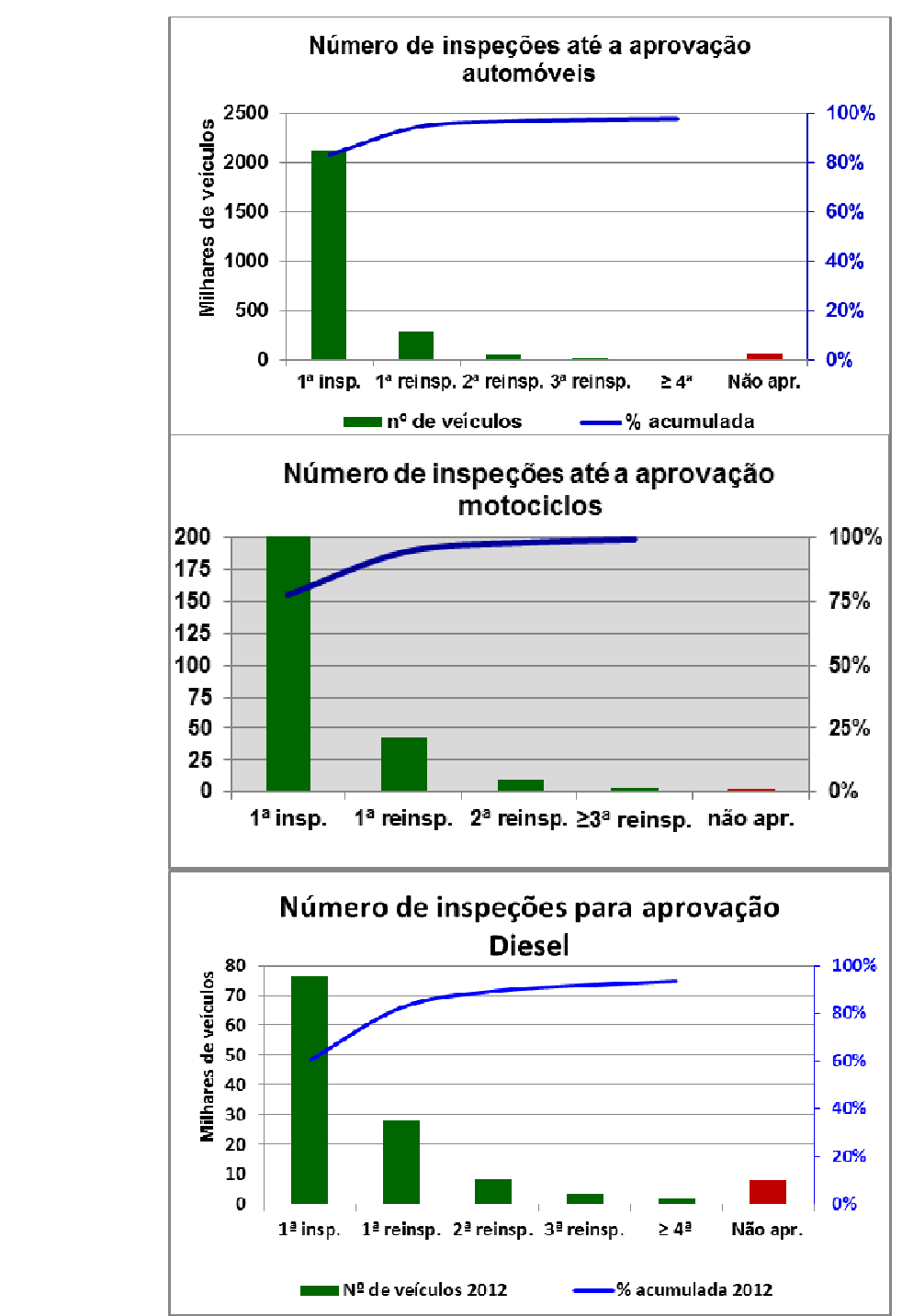

Figura 2.4 - Evolução das aprovações no exercício 2012

Pode-se observar que dentre os veículos não aprovados na primeira inspeção a grande maioria obtém a aprovação logo na primeira reinspeção, sendo mínimo o residual que não chega a ser aprovado durante o ano-exercício, o que mostra que os problemas encontrados podem ser sanados com relativa facilidade para todos os tipos de veículos, independente da idade ou padrão tecnológico. Apenas no caso dos veículos Diesel o percentual final de não aprovados é significativo, mesmo assim, atingindo apenas $6 \%$ dos casos.

O enorme volume de dados de boa qualidade gerado anualmente permite, ainda, a elaboração de análises com alta confiabilidade queseria impossível de se desenvolver sem um programa que permitisse a verificação da grande maioria da frota periodicamente. Este é o caso das curvas de quilometragem anual percorrida pelos diversos tipos de veículos em função da idade. A simples amostragem de leituras do hodômetro dos veículos não permite a elaboração de curvas confiáveis uma vez que estes muitas vezes são trocados devido a quebras ou defeitos (principalmente no caso dos motociclos), são mantidos sem funcionar por quebra do 
cabo de conexão (nos veículos mais antigos, com hodômetros analógicos) ou mesmo são adulterados para reduzir a marcação de quilometragem e aumentar o valor de revenda do veículo. Como os veículos são inspecionados anualmente, a leitura do hodômetro também é feita com a mesma frequência, de forma que as estatísticas podem ser feitas com base na diferença de um ano para outro de cada veículo, o que confere muito maior confiabilidade, uma vez que os dados incongruentes podem ser facilmente eliminados (redução da quilometragem de um ano para outro, por exemplo). A figura 2.5 mostra exemplos de curvas de quilometragem obtidas.

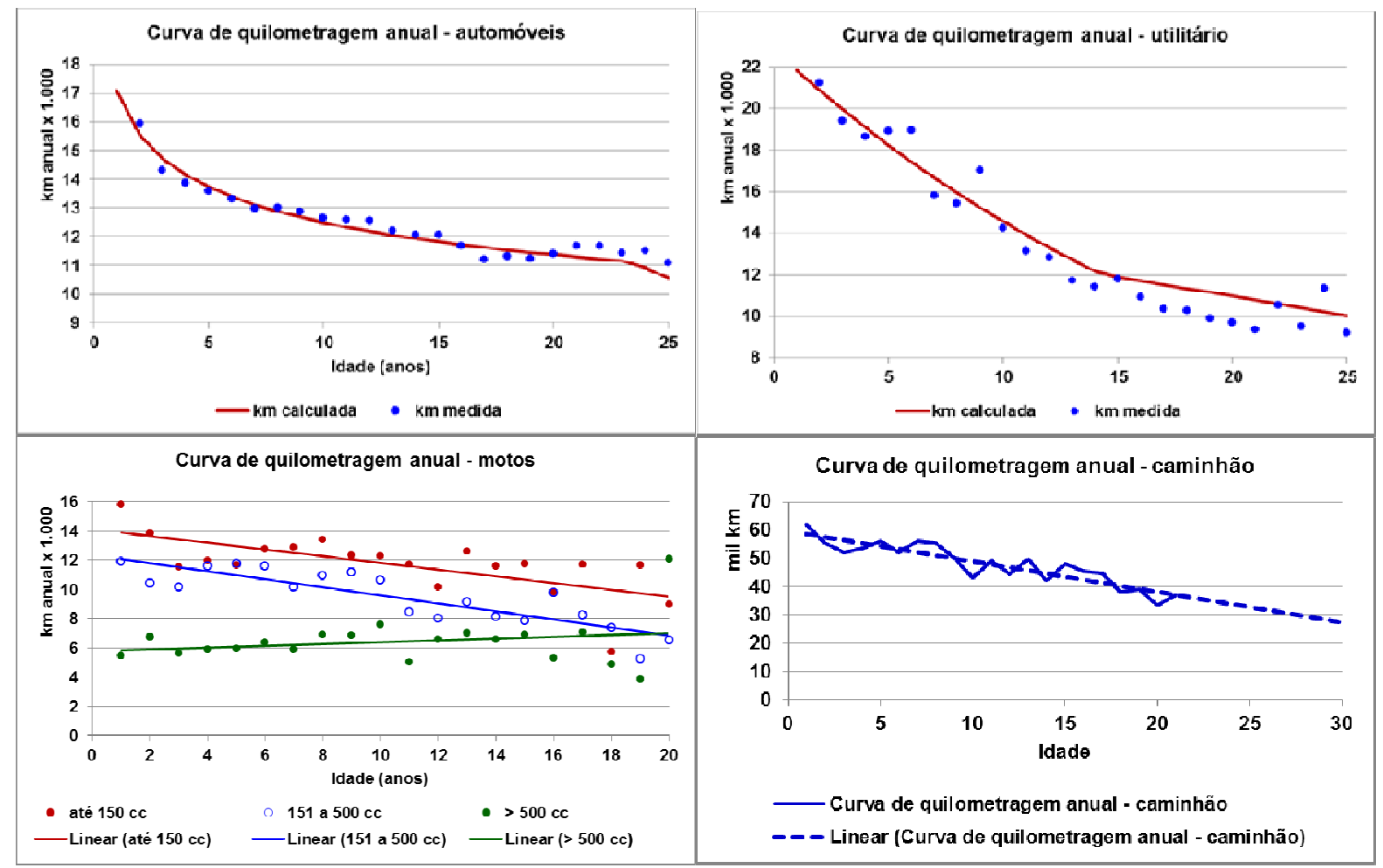

Figura 2.5 - Exemplos de curvas de quilometragem

Este estudo também resultou em uma curva de probabilidade de utilização de veículos leves pela população em função do trajeto diário percorrido, fator fundamental para o cálculo do consumo médio de combustível de veículos híbridos com capacidade de recarga externa (plug-in), que serão lançados no Brasil.

\section{Análise das concentrações medidas}

As análises desenvolvidas até este ponto referem-se aos resultados qualitativos - aprovação, reprovação e rejeição - das inspeções, que permitem avaliar em detalhe o processo de inspeção, bem como o estado geral das frotas envolvidas. Entretanto, para se avaliar diretamente a possibilidade ou necessidade de estabelecimento de novos valores de referência ou o impacto efetivo do Programa I/M-SP sobre o ambiente é necessário trabalhar com os valores de concentração efetivamente medidos. 
As medições de emissões em elevada quantidade permitem a determinação precisadas distribuições estatísticas. A melhor ferramenta estatística para a avaliação dos valores de referência é a análise de curvas percentílicas, que correspondem a um resumo estatístico de todo o universo de dados válidos. Assim, as curvas percentílicas das concentrações medidas de CO dos automóveis para cada fase do PROCONVE, por exemplo, mostrarão quais os comportamentos padrão de cada tecnologia em relação a este poluente, os percentuais de casos em que a emissão é excepcionalmente baixa e os percentuais em que os valores são excessivos, além do que seria desejável (figura 3.1).

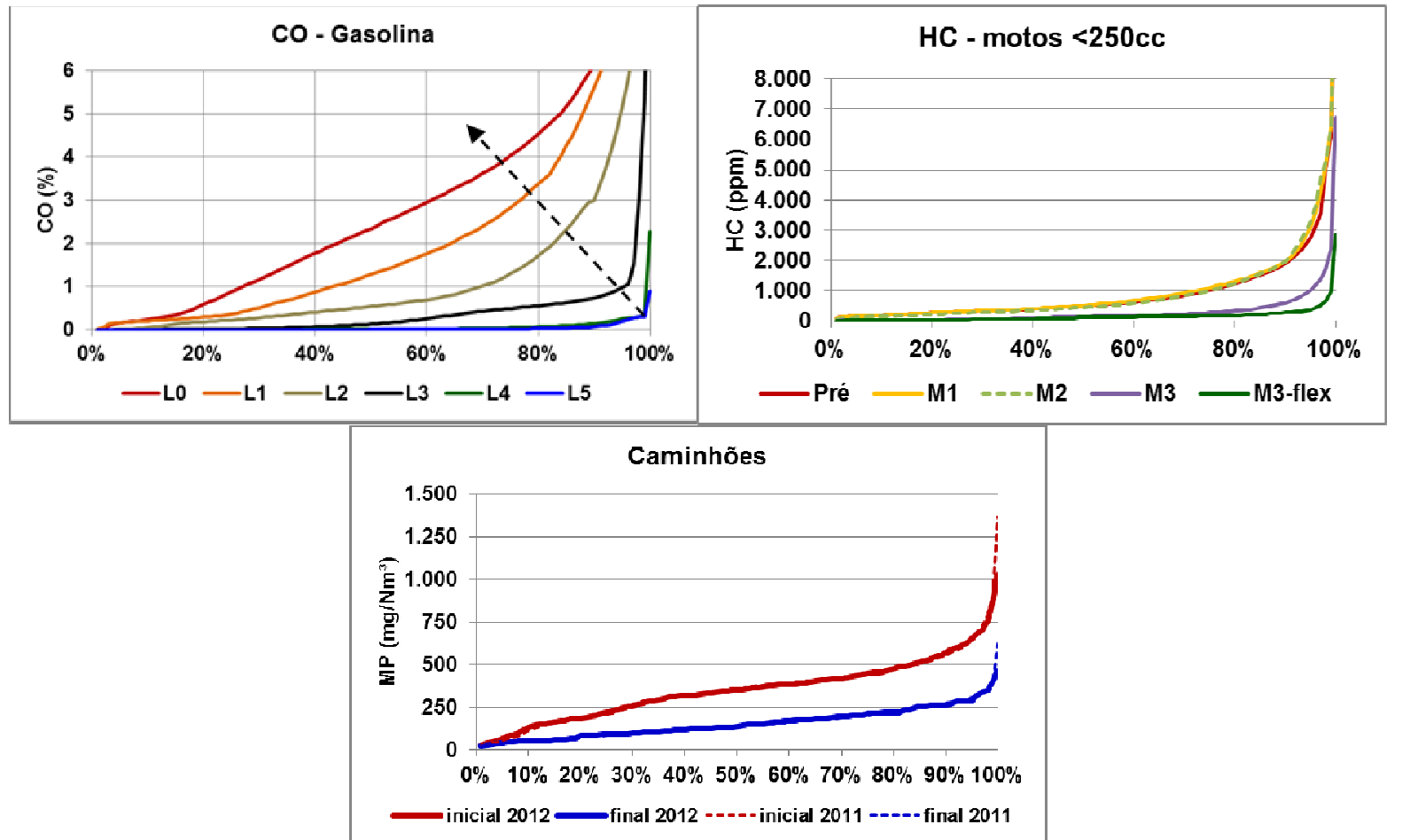

Figura 3.1 -Exemplos de curvas percentílicas para os principais tipos de veículos

Na figura 3.1 são mostrados os casos mais representativos das emissões de cada tipo de veículo, com diferentes enfoques.

O primeiro gráfico mostra o comportamento das emissões de $\mathrm{CO}$ dos automóveis a gasolina, que possuem frotas significativas de todas as fases do PROCONVE, onde cada curva resume o comportamento dos veículos de uma fase. Nessas curvas é possível verificar que o PROCONVE não apenas estabeleceu padrões distintos de emissão de CO para os veículos novos, mas essa diferenciação se manteve ao longo do tempo. As únicas fases que apresentam comportamento semelhante são a L4 e a L5, compostas por veículos de tecnologia moderna. Mesmo neste caso, as curvas correspondentes de $\mathrm{HC}$ (não exibidas aqui) mostram distinção clara.

Essas mesmas curvas são utilizadas para se revisar os valores de referência estatísticos para o Programa I/M-SP. Tomando ainda como exemplo o primeiro 
gráfico, a partir de um valor nitidamente identificado no ponto de inflexão da curva dos veículos mais novos, a seta inclinada (ortogonal às curvas mais baixas nospercentisde $95 \%$ a $99 \%$ ) indica os valores mais plausíveis para as demais tecnologias, de uma forma equilibrada entre restrição tecnológica e benefício ambiental. Esta seta divide a frota em dois conjuntos: os veículos considerados de alta emissão (acima da seta) e os veículos "em estado normal de emissão". Porém, a escolha dos limites deve ser feita de forma a manter uma proporção não exagerada de reprovação de cada grupo, para não inviabilizar o Programa e dar margem suficiente para o desgaste natural e aceitável dos veículos. À medida que a rede de reparação e a sociedade conseguirem melhores resultados, estas curvas se modificam e novas revisões serão possíveis, até que sejam atingidos valores mais próximos aos efetivamente certificados quando estes mesmos veículos eram novos.

No caso dos motociclos(segundo gráfico), a figura mostra as curvas de HC para cada fase do PROMOT, através das quais é possível verificar que as fases M1 e M2 não tiveram efeito que perdurasse ao longo da vida útil dos veículos, apresentando atualmente comportamento idêntico ao dos motociclos anteriores ao PROMOT. Já a fase três aparentemente produziu um efeito bastante importante, embora os motociclos pertencentes a essa fase ainda sejam relativamente novos, sendo necessário prosseguir o estudo por maiorperíodo para verificar se tal diferenciação realmente permanece ao longo do tempo. Deve-se notar, ainda, que a tecnologia flex aplicada a uma parcela dos motociclos da fase M3 mostra resultados significativamente melhores em relação aos demais motociclos da mesma fase.

O último gráfico mostra uma abordagem distinta aplicada à frota de caminhões, onde a curva vermelha representa a emissão de material particulado na inspeção inicial e a curva azul, na última inspeção dos veículos no ano-exercício, após as sucessivas reparações e reinspeções a que foram submetidos, correspondendo às curvas tracejadas ao ano-exercício de 2011 e as linhas cheias ao de 2012. Neste gráfico é possível verificar que o Programa apresenta uma grande coerência de resultados entre os dois anos consecutivos, e que em ambos os casos a frota terminou o processo de inspeção com emissão significativamente reduzida em relação à forma como se apresentava no início.

Em todos os casos, observa-se que o comportamento normal verificado nas percentílicas caracteriza que valores normais dos veículos em bom estado de manutenção são menores do que os limites fixados CONAMA - mais próximos dos valores de certificação, o que permite associar os resultados do I/M-SP com os padrões tecnológicos definidos pelo PROCONVE e calcular os impactos ambientais do Programa em todas as situações.

Embora as percentílicas mostradas sejam apropriadas para redefinir os valores de referência para a inspeção, é sempre importante avaliar individualmente as estatísticas de cada modelo envolvido para verificar se a alteração não prejudicará alguma tecnologia, marca ou modelo em particular, que eventualmente não consiga se manter dentro de limites menores de emissão. No caso dos veículos Otto - automóveis ou motociclos - deve-se, ainda, considerar a dependência entre $\mathrm{CO}$ e HC de cada modelo, pois uma redução excessiva da emissão de CO pode acarretar falhas de combustão com grande elevação da emissão de HC. A título de 
ilustração, a figura 3.2 apresenta o grau de dependência entre as emissões de $\mathrm{CO}$ e $\mathrm{HC}$ para os motociclos M3 com menos de $250 \mathrm{cc}$, indicando o percentil p90 de HC em função do valor de CO observado. Este gráfico, levantado a partir de 12 mil inspeções, comprova a inviabilidade dos limites estabelecidos pela Resolução CONAMA no 418/2009 para a fase M3 e atesta o acerto na definiçãodos limites estabelecidos pela Resolução 451/2012.

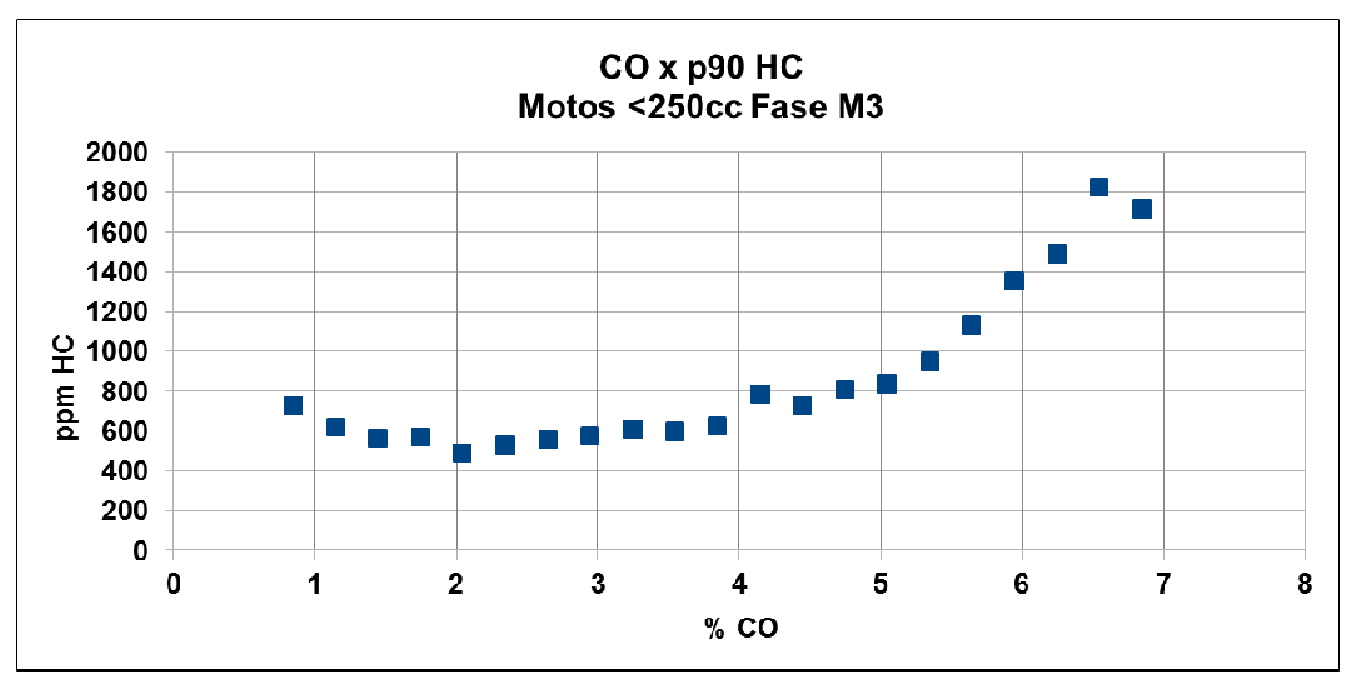

Figura 3.2 - Curvas de dependência das emissões de CO e HC

As reduções de emissões observadas através das curvas percentílicas são amplamente confirmadas ao se compararem as médias das concentrações medidas nos veículos aprovados na primeira inspeção, reprovados na primeira e na última inspeção dos reinspecionados (figura 3.3). 

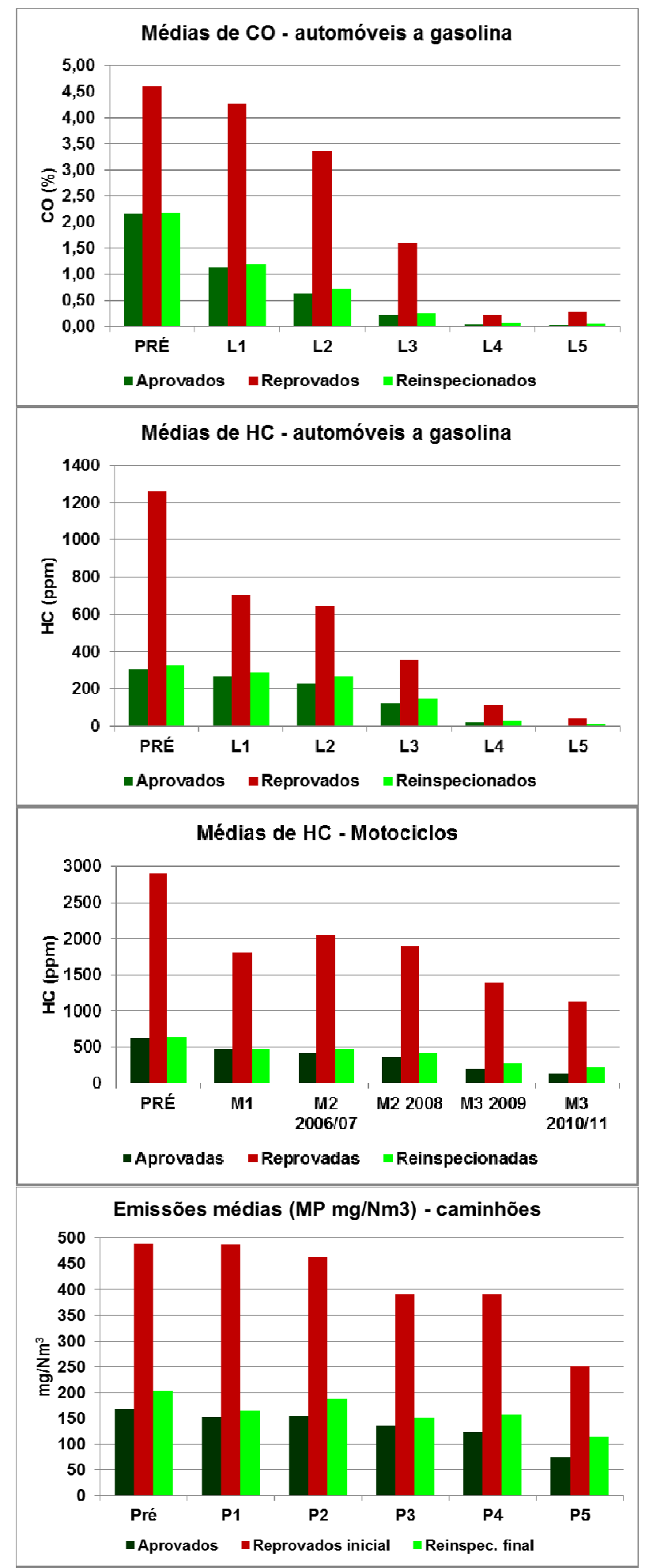

Figura 3.3 - Média das emissões dos veículos por tecnologia, tipo e resultado da inspeção

Inicialmente pode-se verificar que em todos os casos a redução das emissões dos veículos inicialmente reprovados (colunas vermelhas) é bastante significativa, 
produzindo resultados ao final do processo (colunasem tom verde claro) similares aos dos veículos bem mantidos, representados pelos aprovados na primeira inspeção (colunasem tom verde escuro).

No caso dos automóveis, fica evidente também a diferenciação produzida pelo PROCONVE, principalmente no caso das emissões de CO, onde os níveis de emissão dos veículos bem mantidos são gradativamente menores a cada nova fase do PROCONVE.

Nos motociclos, conforme comentado anteriormente acerca das curvas percentílicas, reduções significativas das emissões de $\mathrm{HC}$ ocorrem somente na fase M3, embora neste gráfico seja possível notar uma certa diferenciação entre os veículos pré-PROMOT e M1. Note-se que neste caso as fases M2 e M3 possuem subdivisões (M2-2008 e M3-2009), pois em 2008 começaram a ser fabricados motociclos da fase M3, caso, por exemplo, dos flex que começaram a ser produzidos nesta época, enquanto que em 2009 ainda foi permitida a produção de veículos da fase M2 devido à crise econômica de 2008. Note-se que essa diferenciação é efetivamente válida, posto que por um lado os motociclos da fase M2-2008 possuem média de emissão ligeiramente abaixo dos M2 típicos (fabricados entre 2006 e 2007), enquanto que os M3-2009 emitem mais que os de 2010 e 2011.

No caso dos caminhões ocorre fato semelhante ao dos motociclos, com as fases iniciais do PROCONVE surtindo pouco efeito. Notam-se três níveis claros de emissões: dos veículos anteriores ao PROCONVE aos da fase P2; dos veículos P3 e P4; e dos veículos P5.

A análise das médias das emissões também permite avaliar a evolução do Programa $\mathrm{I} / \mathrm{M}$ e verificar o impacto do uso de tecnologias diferentes ou de modificações frequentes na frota, como a conversão para GNV (figura 3.4). 


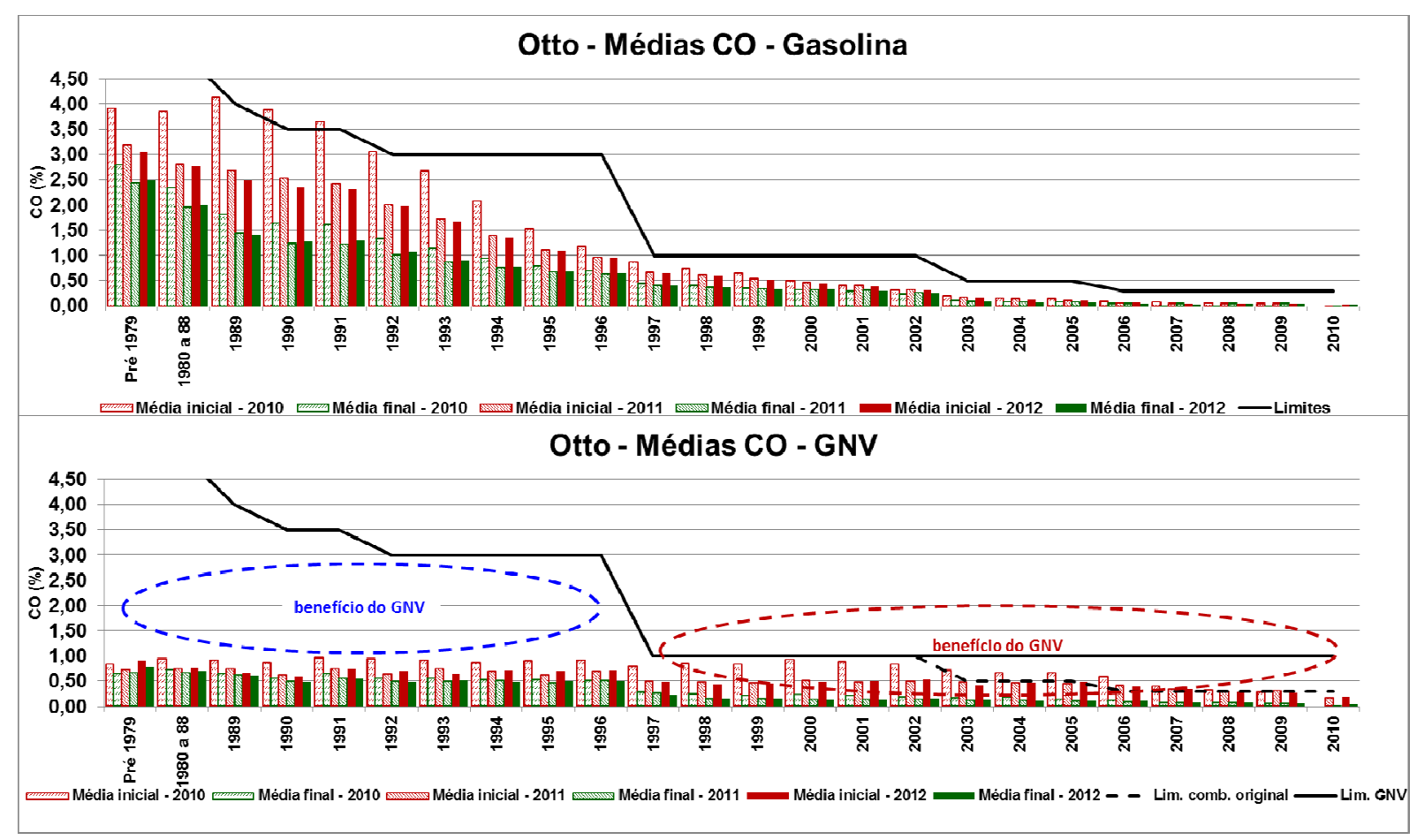

Figura 3.4 - Comparação entre as médias de emissões de CO e os parâmetros de referência

A figura 3.4 mostra as emissões médias iniciais e finais (primeira e última inspeção de cada veículo) em três anos consecutivos e para dois grupos de veículos. Inicialmente, pode-se verificar que as emissões caíram fortemente de 2010 para 2011, para todas as idades de veículos, estabilizando-se na comparação 2011/2012. Como esta redução ocorre inclusive nas emissões iniciais, pode ser considerada como um ganho inicial permanente do Programa, que tende a se manter nos próximos anos, ao menos enquanto for mantido o Programa I/M-SP nos moldes atuais.

A comparação entre os veículos originais e os convertidos para GNV nos mostra duas situações claramente distintas, de forma que, ao menos em relação ao CO, a conversão realmente reduz as emissões dos veículos carburados, permitindo, inclusive, que se adotem valores de referência mais restritivos, a serem confirmados para todos os modelos legalmente convertidos. Por outro lado, a partir do momento em que os veículos com controle eletrônico passaram a ser predominantes na frota a situação se inverte, indicando que estes veículos não são apropriados para se fazer qualquer alteração significativa, o que demonstra a validade e importância da decisão do CONAMA em não homologar kits de conversão para modelos 2007 e posteriores, aliás, de acordo com estas estatísticas verifica-se que tal proibição poderia ser estendida pelo menos até 2003.

De uma forma geral, os ganhos obtidos pelo Programa I/M-SP podem ser caracterizados pelas parcelas exibidas na figura 3.5, entretanto,as relações encontradas nestas médias gerais refletem os ganhos percentuais relativos, mas 
ainda carecem de uma ponderação pelos fatores de emissão característicos de cada ano de fabricação para a obtenção dos benefícios ambientais do Programa I/M-SP estimados sobre a produção anual de poluentes da frota, que será apresentado adiante. Estas reduções são semelhantes em todos os tipos de veículos.

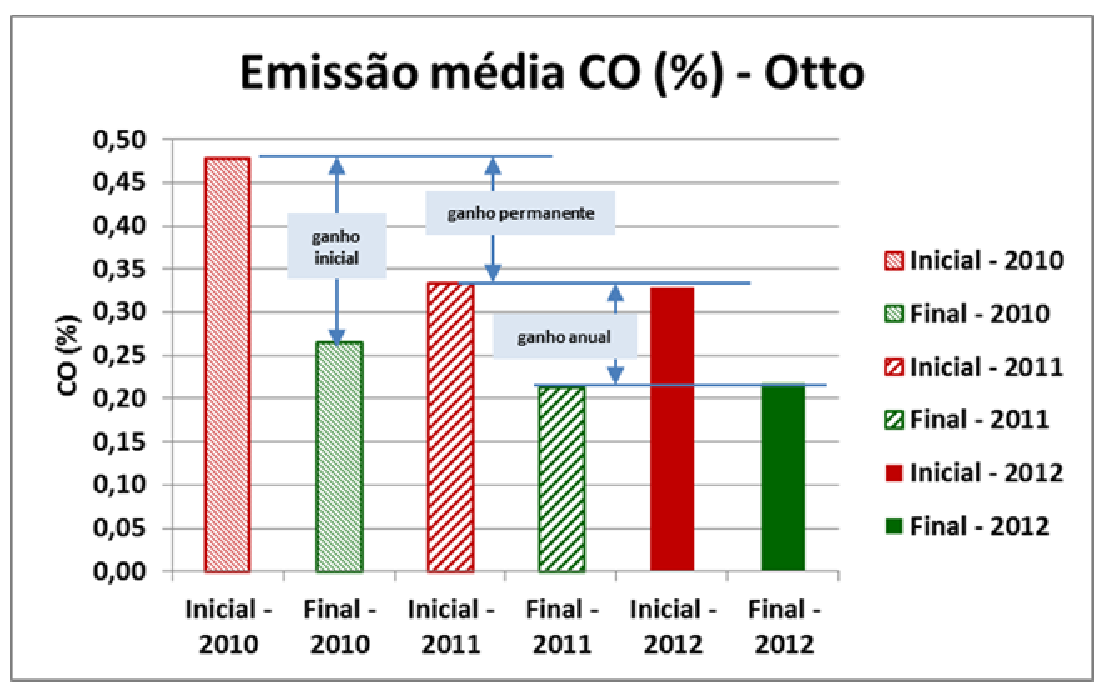

Figura 3.5 - Evolução das médias das concentrações de $\mathrm{CO}$ da frota de veículos do ciclo Otto entre 2010 e 2012

\section{Estimativas do benefício ambiental do Programa I/M-SP}

Para o cálculo das emissões totais e do efeito ambiental do Programa, foi seguida a metodologia publicada no XX SIMEA - Simpósio Internacional de Engenharia Automotiva, em 2012, no trabalho "Critérios de Avaliação da Eficácia do Programa de Inspeção Veicular"’.

Os benefícios ambientais do Programa I/M-SP são estimados através do cálculo das reduções de emissão anual em massa, de acordo com os seguintes passos:

a) cálculo das médias das concentrações de $\mathrm{CO}$ e $\mathrm{HC}$ medidas na primeira inspeção (INICIAIS) de todos os veículos inspecionados, independentemente de serem aprovados, reprovados ou rejeitados, por ano de fabricação e tipo de veículo;

b) a emissão dos veículos rejeitados por motivos diretamente relacionados com emissão alta é assumida como sendo igual à média dos reprovados. Nos demais motivo éassumida como sendo a média geral, cujos valores são conhecidos;

c) cálculo das médias dos resultados das inspeções FINAIS (última inspeção), por ano de fabricação e tipo de veículo. Os veículos aprovados na primeira inspeção também são incluídos na média final, pois eles apresentam 0 mesmo resultado antes e depois da inspeção;

d) cálculo da emissão anual FINAL, em massa, de cada frota (todos os veículos APÓS as inspeções), separadamente por ano de fabricação e tipo de veículo, 
dada pelo produto do número de veículos pelo fator de emissão certificado e pelo fator normal de deterioração e pela quilometragem anual, característicos da cada grupo;

e) cálculo da emissão anual INICIAL, em massa, de cada frota (todos os veículos ANTES das inspeções), dada pela emissão FINAL calculada em "d" acrescida das diferenças percentuais das médias INICIAL e FINAL determinadas em "a" e "c", ANTES e DEPOIS da inspeção;

f) cálculo da soma das massas emitidas anualmente de $\mathrm{CO}$ e $\mathrm{HC}$ pelas frotas acima caracterizadas para a estimativa da emissão total antes e depois dos efeitos das inspeções e a proporção média de redução da frota como um todo;

g) cálculo das percentagens de redução da emissão anual em massa, para cada grupo de veículos, por ano de fabricação, expressa em "veículos equivalentes", isto é o número de veículos que fariam o mesmo efeito ambiental se fossem retirados das ruas, para cada ano de fabricação e tipo de veículo.

A figura 4.1 mostra o resultado do benefício ambiental obtido em CO para os automóveis, em HC para os motociclos e em MP para os veículos do ciclo Diesel.

Os gráficos da figura acima são exemplos que resumem o quadro das emissões finais e benefícios obtidos pelo Programa I/M-SP em 2012 para CO dos automóveis, HC dos motociclos e MP dos veículos Diesel em termos de porcentagem das respectivas emissões iniciais. As colunas apresentadas sem preenchimento correspondem às emissões evitadas, ou seja, o que foi reduzido da emissão de cada parcela exibida. Assim, para cada tipo de veículo é possível comparar diretamente as emissões de cada poluente para cada combustível (no caso dos automóveis), tamanho de motor (nos motociclos) ou classe de veículo (Diesel); e verificar as reduções obtidas para os diferentes níveis tecnológicos, representados pelas fases do PROCONVE/PROMOT. 


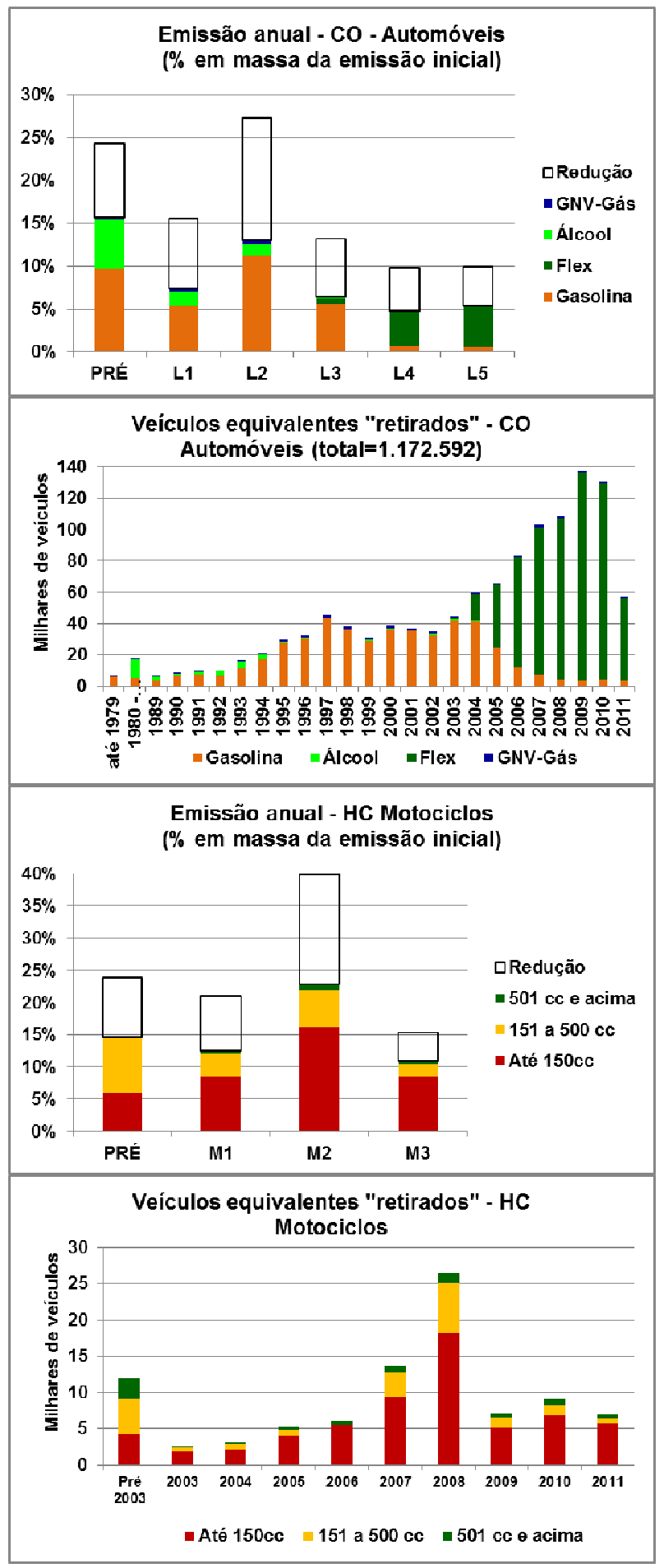




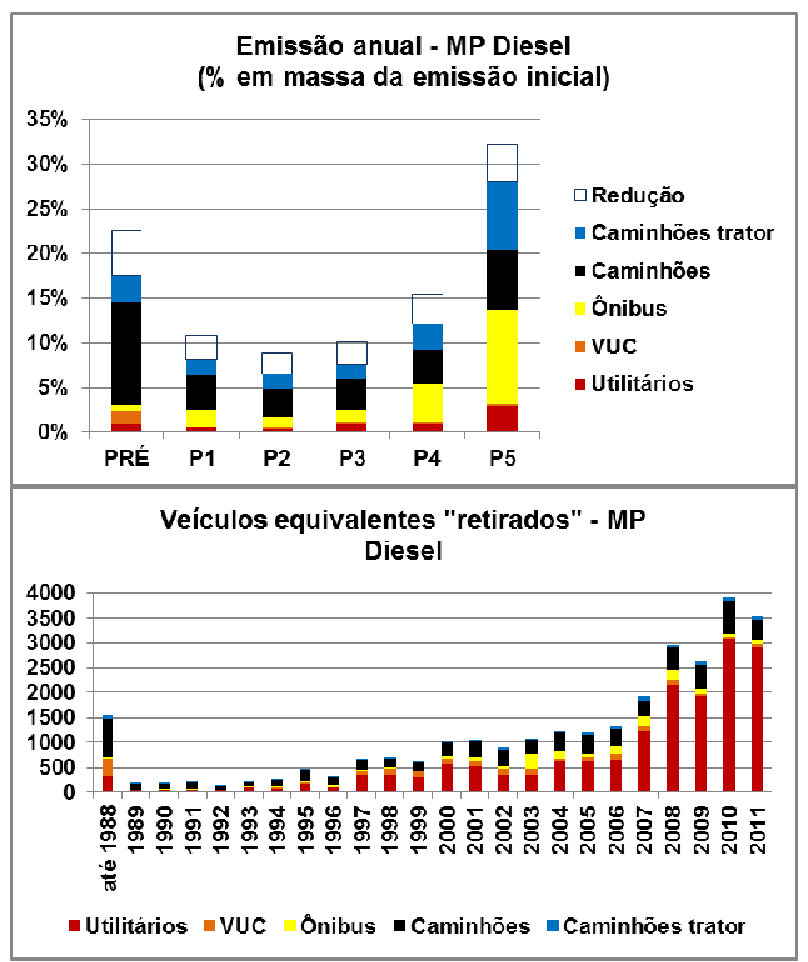

Figura 4.1 - Distribuições da emissão anual e das reduções obtidas pelo I/M

As reduções mostradas variam em função da tecnologia (que influenciam nos fatores de emissão diretamente) e da frota, motivo pelo qual as emissões dos automóveis da fase L4 ou L5 são superiores à metade da dos veículos anteriores ao PROCONVE, cujo fator de emissão de CO original é da ordem de 100 vezes maior.

Outra abordagem para exprimir o benefício ambiental do Programa I/M pode ser adotada convertendo as reduções percentuaisem "veículos equivalentes de mesma tecnologia". Esta abordagem, mostrada nos gráficos da direita na mesma figura, é mais intuitiva, pois mostra quantos veículos daquela tecnologia teriam que ser retirados de circulação para produzir o mesmo efeito ambiental obtido com a manutenção adequada daquela frota obtida pelo I/M-SP.

\section{Efeitos da Lei $15.688 / 2013$}

Em 11 de abril de 2013 foi promulgada a Lei Ordinária №15.688 do Município de São Paulo, que altera a idade mínima e a frequência para realização da inspeção de todos os veículos do ciclo Otto, inclusive motociclos. Segundo o texto da referida Lei, para todos os veículos excetuando-se a frota a Diesel, ficam "dispensados da inspeção os veículos novos nos 3 (três) primeiros exercícios, incluindo o ano em que o primeiro licenciamento foi ou deveria ter sido realizado"; e a inspeção deverá ser "bienal, devendo ser realizada no $3^{\circ}$ (terceiro) exercício após o ano em que o primeiro licenciamento foi ou deveria ter sido realizado e, a partir daí, em exercícios alternados". 
Conforme demonstrado neste trabalho, entretanto, a inspeção veicular produz resultados importantes também em relação aos veículos de menos de três anos (figuras 3.3, 3.4 e 4.1), e as reduções de emissões médias obtidas em um dado anoexercício são parcialmente perdidas de um ano para outro (figura 3.5), de forma que ambas as medidas serão certamente prejudiciais ao controle das emissões veiculares.

Adicionalmente, deve-se considerar que todos os fabricantes exigem que os veículos sejam revisados no mínimo a cada ano de uso, para não perderem a garantia, de forma que a inspeção anual possui, ainda, a virtude de monitorar e auditar a qualidade das revisões desde o início de sua vida útil.O Programa I/M-SP é o único dispositivo existente e implantado para esta finalidade, sendo que os seus benefícios se mostram tanto maiores quanto mais frequentes foremas inspeções, sendo desejável (e obrigatória segundo o CONAMA) a frequência anual após o primeiro ano de uso.

O aumento contínuo das emissões de um veículo sem manutenção e o efeito corretivo produzido por manutenções periódicas, as quais passam a ser obrigatórias com a exigência de inspeções anuais, pode ser visto na figura $5.1^{\text {1i }}$

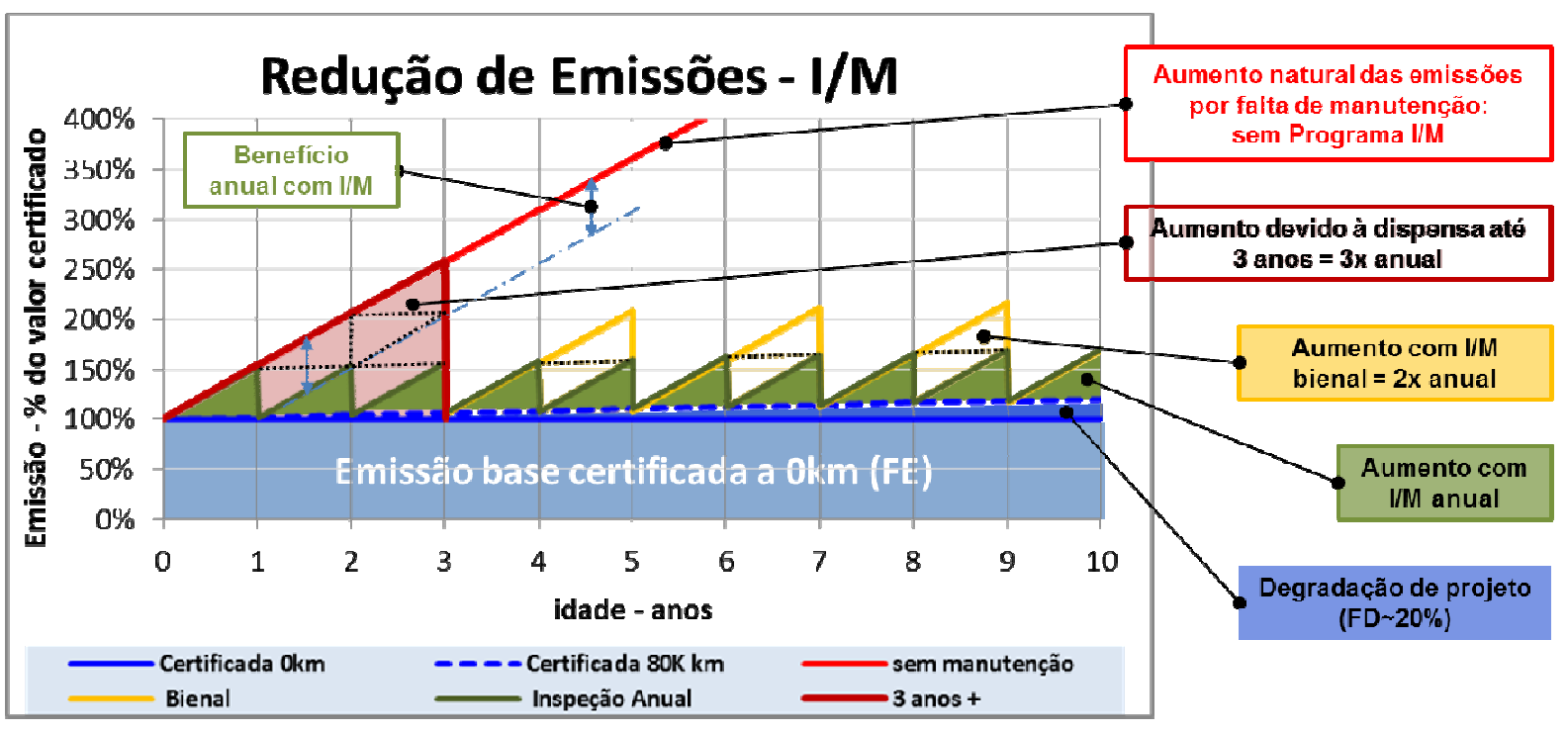

Aumento anual das emissões = área sob a curva característica do Programa I/M

Figura 5.1 - Benefícios ambientais periódicos do Programa I/M

A linha vermelha mostra o crescimento das emissões em um veículo sem manutenção. Cada vez que o veículo é submetido a uma revisão e retorna ao estado de conformidade com as especificações de fábrica, o fator de emissão é reduzido, retornando à linha tracejada azul, que corresponde ao fator de deterioração de um veículo em perfeitas condições de manutenção (degradação normal). Com a obrigatoriedade da inspeção anual, as emissões permanecem próximo ao nível normal, dentro da área verde do gráfico. Com inspeções mais espaçadas, como prevê a lei para veículos com menos de 10 anos, os valores de emissão podem atingir as áreas sombreadas em vermelho (dispensa dos três primeiros anos, que 
permite uma degradação média três vezes maior) e amarelo (inspeção bienal, que permite uma degradação média duas vezes maior).

Esse impacto será produzido sobre as emissões de $\mathrm{CO}$ e $\mathrm{HC}$, uma vez que a lei adota esses critérios para todos os veículos leves e motocicletas do ciclo Otto. Uma estimativa inicial simulada sobre os resultados de 2012 indica que esses impactos podem chegar a aproximadamente $60 \%$ dos benefícios atuais, sendo metade relativa à possibilidade de fraudes devida à descentralização das inspeções, que poderão ser realizadas em centenas de oficinas mecânicas e/ou Organismos de

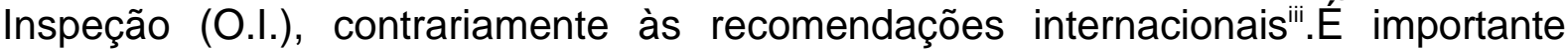
notar que após a implantação do I/M-SP, o número de dias com qualidadedo ar regular por $\mathrm{CO}$ caiu sistematicamente à metade dos anos anteriores, conforme demonstrado pela CETESB em $2013^{\mathrm{iv}}$.

\section{Conclusões e recomendações}

As médias das emissões dos veículos reprovados foram consideravelmente reduzidas para todos os poluentes, tipos de veículos e combustíveis, retornando aos mesmos níveis dos veículos aprovados, indicando ser decorrente de problemas de manutenção, cuja reparação é viável;

A recuperação dos veículos é factível e demonstrada em poucas reinspeções, que levam a frota a níveis entre $96 \%$ e $99 \%$ de aprovação final;

Os veículos com injeção eletrônica convertidos para GNV, constituem exceção a esta regra, e comprovam o comprometimento das suas especificações originais, quando alterados à revelia dos critérios do fabricante do veículo;

Os veículos com motor flex, por terem tecnologia de injeção eletrônica mais moderna e atualizada apresentam melhor resultado para a quase totalidade da frota;

Essas reduções ponderadas pela frota, com seus fatores de emissão originais e intensidade de uso dos veículos, produziu o benefício ambiental estimado em 30\% para o material particulado, $50 \%$ para $\mathrm{CO}$ e $40 \%$ para $\mathrm{HC}$ em massa anual de poluentes emitidos pela frota inspecionada;

Comparando-se os resultados no período 2010 - 2012, comprova-se que o benefício ambiental é composto de ganhos permanentes decorrentes do aprendizado da sociedade e outro variável que se renova anualmente, o que justifica e reforça a decisão do CONAMA pela periodicidade anual das inspeções;

As modificações introduzidas pela nova lei municipal diminuem significativamente a eficácia do programa e poderão, com a pulverização da inspeção, afetar de forma irreparável a sua confiabilidade junto à população;

Como um efeito paralelo, o Programa produziu uma grande massa de dados, que permite o conhecimento técnico aprofundado das frotas circulantes, que permitirão a realimentação de informações para 0 aprimoramento do PROCONVE/PROMOT para a fabricação de veículos limpos e do próprio Programa I/M, pela revisão dos parâmetros de referência; 
Este levantamento de dados também trouxe informações precisas sobre a intensidade de uso da frota por tipo e idade dos veículos, que são fundamentais para o aprimoramento dos inventários de emissão, das normas de ensaio e subsidiar o aprimoramento das políticas públicas de transporte e de redução da poluição do ar.

SIMEA 2013 Programa I_M SP - 9.6.13

\section{Bibliografia}

i Branco, G.M.; Croce, W.D.A.; Branco, F.C.; Szwarc, A.; Napoleone, J.M. - Critérios de Avaliação da Eficácia do Programa de Inspeção Veicular - Trabalho apresentado no XX SIMEA em São Paulosetembro de 2012.

iiEdward L. Glover; Dave Brzezinski - MOBILE6 Inspection/Maintenance Benefits - Methodology for 1981 through 1993 Model Year Light Vehicles - EPA420-P-99-007 - 1999.

iii Hausker K. etalii - Vehicle Inspection and Maintenance Programs: International Experience and Best Practices.- United States Agency for International Development- USAID, Office of Energy and Information Technology, 2004.

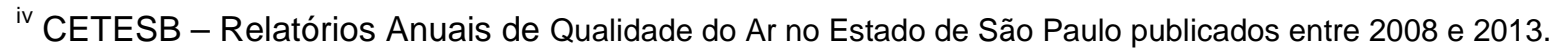

